\title{
Employment and insurance for young adults with congenital heart disease
}

\author{
David S Celermajer, John E Deanfield
}

\begin{abstract}
Objective-To determine the life and health insurability and employability of young adults with congenital heart disease.

Design-Questionnaire study.

Setting-Cardiac department of a tertiary referral hospital for children.

Patients-Young adults 18-30 years old with a variety of congenital heart defects, both simple and complex, including postoperative patients.
\end{abstract}

Main outcome measures-Availability of insurance at normal or high rates, with or without special conditions or exclusions. Prospects for employment.

Results-Questionnaires were sent to eight large life insurance companies, five health insurance companies and, 15 employers, and 26 replies were received (93\%). The consensus for life insurability was that young adults with mitral valve prolapse without regurgitation, postoperative ductus arteriosus, and aortic coarctation were insurable at standard rates. Those with any of the other heart defects listed were either insurable at high rates, or in the case of many lesions, not insurable at all. The consensus for health insurance was that insurance was available, but with complete exclusion of benefit for the cardiac disorder. Employment prospects were good for those with simple defects, but poorer for those with complex lesions.

Conclusions-Prospects for insurance and employment for young adults with complex congenital heart lesions are poor. Inconsistencies found in insurance and job policies may be due to lack of appropriate guidelines for the outcome of young adults with corrected and uncorrected congenital heart disease.

(Br Heart f 1993;69:539-543)

Cardiothoracic Unit, The Hospitals for Sick Children, Great Ormond Street, London D S Celermajer J E Deanfield

Correspondence to: D S Celermajer Cardiothoracic Unit, The Hospitals for Sick Children Great Ormond Street, London WCIN 3JH.

Accepted for publication 8 February 1993
Recent advances in medical and surgical treatment of congenital heart disease have led to the survival of increasing numbers of young adults with a range of cardiovascular abnormalities. It is estimated that over 500000 patients with congenital heart disease have reached adulthood in the last 30 years in the United States alone, ${ }^{1}$ and of these about $90 \%$ are symptom free and well. ${ }^{2}$ Employment prospects and insurability of these young adults are practical aspects of life about which many patients and their parents have concern, but few data are available. The American Heart Association has published recommendations on life insurance ${ }^{3}$ and health insurance, ${ }^{4}$ but no such guidelines exist in the United Kingdom. In particular, the extent to which insurance companies agree with American guidelines or with each other for rating young adults with congenital heart disease is not known.

Employability of this population may be based on current cardiovascular state, the likely sickness and absence record, possible premature curtailment of career, and pension planning. No guidelines for employment of these patients are currently available. Some larger employers (for example Royal Mail, British Telecom) have established occupational health services, and may therefore seek employment advice from their occupational physicians for individual applicants. For the vast majority of employers who do not have occupational health advisors, however, the absence of employment guidelines is likely to result in inconsistencies of policy. We therefore undertook this survey to find the employment and insurance prospects for young adults with congenital heart disease in the United Kingdom.

\section{Methods}

INSURANCE

A questionnaire covering 20 common congenital heart defects before and after operation (see table 1 and appendix) were sent to eight of Britain's largest life insurance companies and to five of Britain's largest health insurance companies. This included simple stratification of lesion severity where appropriate. Companies were asked to assume that in each case the applicant was 18-25 years old and symptom free, and to state whether the subject was insurable at standard rates, high rates, or not at all.

\section{EMPLOYMENT}

Questionnaires were sent to 15 employers. These covered the conditions of repaired septal defects, repaired tetralogy of Fallot, repaired coarctation of the aorta, valve replacement, Fontan procedure, Mustard or Senning repair of transposition of the great arteries, and post operative arrhythmia. A less complex questionnaire was sent to employers because few were thought to have medical consultants on the staff (unlike large insurance companies). Answers were sought from 
Life insurability of adults with congenital heart disease

\begin{tabular}{|c|c|c|c|}
\hline Defect & Normal rate & High rates & Decline \\
\hline \multicolumn{4}{|l|}{ AR: } \\
\hline Mild & & $\star$ & \\
\hline Moderate & & * & \\
\hline Severe & & & $\star$ \\
\hline \multicolumn{4}{|l|}{ AS: } \\
\hline Mild & & * & \\
\hline Moderate & & & * \\
\hline Severe & & & * \\
\hline \multicolumn{4}{|l|}{ MR: } \\
\hline Mild & & * & \\
\hline Moderate & & * & \\
\hline Severe & & & * \\
\hline \multicolumn{4}{|l|}{ MS: } \\
\hline Mild & & $\star$ & \\
\hline Moderate & & * & \\
\hline Severe & . & & $\star$ \\
\hline MVP (no regurgitation) & * & & \\
\hline MVR & & * $(1)$ & \\
\hline AVR & & *(1) & \\
\hline Double VR & & & * $(1)$ \\
\hline \multicolumn{4}{|l|}{ PS: } \\
\hline Mild & & $\star(2)$ & \\
\hline Moderate & & $\star(2)$ & \\
\hline Severe & & & * \\
\hline \multicolumn{4}{|l|}{ Ebstein's: } \\
\hline Mild & & & $\star(3)$ \\
\hline Moderate & & & $\star(2)$ \\
\hline Severe & & & $\star$ \\
\hline Postop & & & $\star(3)$ \\
\hline \multicolumn{4}{|l|}{ ASD: } \\
\hline $\mathrm{QP} / \mathrm{QS}<2$ & & $\star$ & \\
\hline $\mathrm{QP} / \mathrm{OS} \geqslant 2$ & & $\star$ & \\
\hline Postop & & $\star(4)$ & \\
\hline \multicolumn{4}{|l|}{ VSD: } \\
\hline $\mathrm{QP} / \mathrm{QS}<2$ & & $\star$ & \\
\hline $\mathrm{OP} / \mathrm{OS} \geqslant 2$ & & $\star$ & \\
\hline Postop normal & & $\star(4)$ & \\
\hline \multirow{2}{*}{\multicolumn{4}{|c|}{$\begin{array}{l}\text { Postop | PVR } \\
\text { PDA: }\end{array}$}} \\
\hline & & & \\
\hline Preop & & & * \\
\hline Postop & $\star$ & & \\
\hline \multicolumn{4}{|l|}{ CoAo: } \\
\hline Mild & & & $\star(3)$ \\
\hline Moderate & & & \\
\hline Severe & & & $\star$ \\
\hline Postop normal & * & & \\
\hline Postop $\uparrow \mathrm{BP}$ & & 夫 & \\
\hline \multicolumn{4}{|l|}{ Tetralogy: } \\
\hline Preop & & & $\star$ \\
\hline Postop & & & $\star(5)$ \\
\hline \multicolumn{4}{|l|}{ TGA: } \\
\hline After Mustard/Senning & & & $\star$ \\
\hline After arterial switch & & & $\star(6)$ \\
\hline \multicolumn{4}{|l|}{ TAPYR: } \\
\hline Postop & & $\star$ & \\
\hline \multicolumn{4}{|l|}{ Truncus: } \\
\hline Postop & & & $\star$ \\
\hline Fontan procedure & & & $\star$ \\
\hline $\mathrm{CCHB}$ & & $\star(7)$ & \\
\hline
\end{tabular}

AR, aortic regurgitation; AS, aortic stenosis; ASD, atrial septal defect; AVR, aortic valve replacement; BP, blood pressure; CCHB, congenital complete heart block; CoAo, coartation of
aorta; MR, mitral regurgitation; MS, mitral stenosis; MVP, mitral valve prolapse; MVR, mitral aorta; MR, mitral regurgitation; MS, mitral stenosis; MVP, mitral valve prolapse; MVR, mitral
valve replacement; PDA, patent ductus arteriosus; Postop, postoperative; PS, pulmonary stenovalve replacement; PDA, patent ductus arteriosus; Postop, postoperative; PS, pulmonary steno-
sis; PVR, pulmonary vascular resistance; QP/QS, pulmonary to systemic shunt; TAPVR, total sis; PVR, pulmonary vascular resistance; QP/QS, pulmonary to systemic shunt; TAPVR, total
anomalous pulmonary venous return; Tetralogy, tetralogy of Fallot; TGA, transposition of the anomalous pulmonary venous return; Tetralogy, tetralogy of Fallot; TGA, transposition of the
great arteries; Truncus, truncus arteriosus; VSD, ventricular septal defect; $\uparrow$, raised; 1, policy limited to 25 years after operation by one company; 2 , normal rates offered for these conditions by two companies; 3 , normal rates offered by one company; 4 , reducing to normal rates after one to four years by two companies; 5 , high rate policy for short duration available from two companies; 6 , high rate policy for limited duration by one company; 7 , declined by one company.

a variety of employers: several large government employers - for example, British Rail, Royal Mail, Army; two large supermarket chains, two hospitals, two large private firms (one legal, one banking), and three small businesses (a newsagent, a dry cleaner, and a building contractor). In every case the insurer or employer was asked their policy for an otherwise healthy and adequately qualified applicant of 18-25 years of age. All replies were treated as confidential for the purposes of publication.

\section{Results}

Replies were received from seven of eight life insurance companies (from the chief or deputy chief underwriter), from all the health insurance companies and from 14 of 15 employers (overall response rate 93\%).

\section{LIFE INSURANCE}

Four insurers responded by answering our questionnaire in full. The table gives the consensus of their responses. There was a highI degree of agreement between companies fore most conditions, but there were some impor 2 tant discrepancies. For example, subjects with mild or post operative Ebstein's anomaly of the tricuspid valve were uninsurable with three of four companies, but insurable at nor $\frac{\bar{D}}{\bar{n}}$. mal rates by the other. Those with congenitaf complete heart block were insurable at highe rates by three of four companies, but weren declined insurance by the other. There were also some inconsistencies in policy for posioperative patients with tetralogy of Fallot double valve replacement, or the arteria $\underline{\square}$ switch procedure for transposition of the great arteries (table).

Three insurers were only able to respond in general terms. Their policies were similar 30 if a defect was of mild or moderate severity of had been corrected, life insurance was available at normal rates, but was subject to are exclusion for the disclosed condition. If the defect was severe, cover might be rejectedo completely. A medical report from the patient's physician would be sought before any applicant was rejected.

\section{HEALTH INSURANCE}

No company responded by answering ouro questionnaire in full. Four companies repliec that if a child is a subscriber at the time of discovery of the heart defect, insurance would continue until the age of 18 or 21 years undez the family policy. Thereafter a new policy must be issued for the person with the hear defect. Any young adult who declares a con? genital heart defect (before or after surgery) would have a policy underwritten to exclude. future benefit for medical or surgical treat $₹$ ment for that condition. None of these foub insurers would reject health insurance com? pletely for these people, but the heart defece would not be insurable. The other company, replied only that all medical underwriting took place on a case by case basis, with refer 0 ence to the patients own physician and the company's medical advisor.

\section{EMPLOYMENT}

Replies were received from 14 companies; and were written by occupational health physicians (four), company medical advisor\$D (four), or directly by company managemen? (six). In general, large government organisa tions and public companies had occupationak health or physician advisors on the staff whereas private firms and small businesses had none, and decisions were made directly. by the employers. The respondents were opti? mistic about job prospects for young adults with simple or totally corrected heart defects, but less favourably disposed to those with complex or only partially corrected problems. 


\section{Appendix: Questionnaire sent to insurance companies}

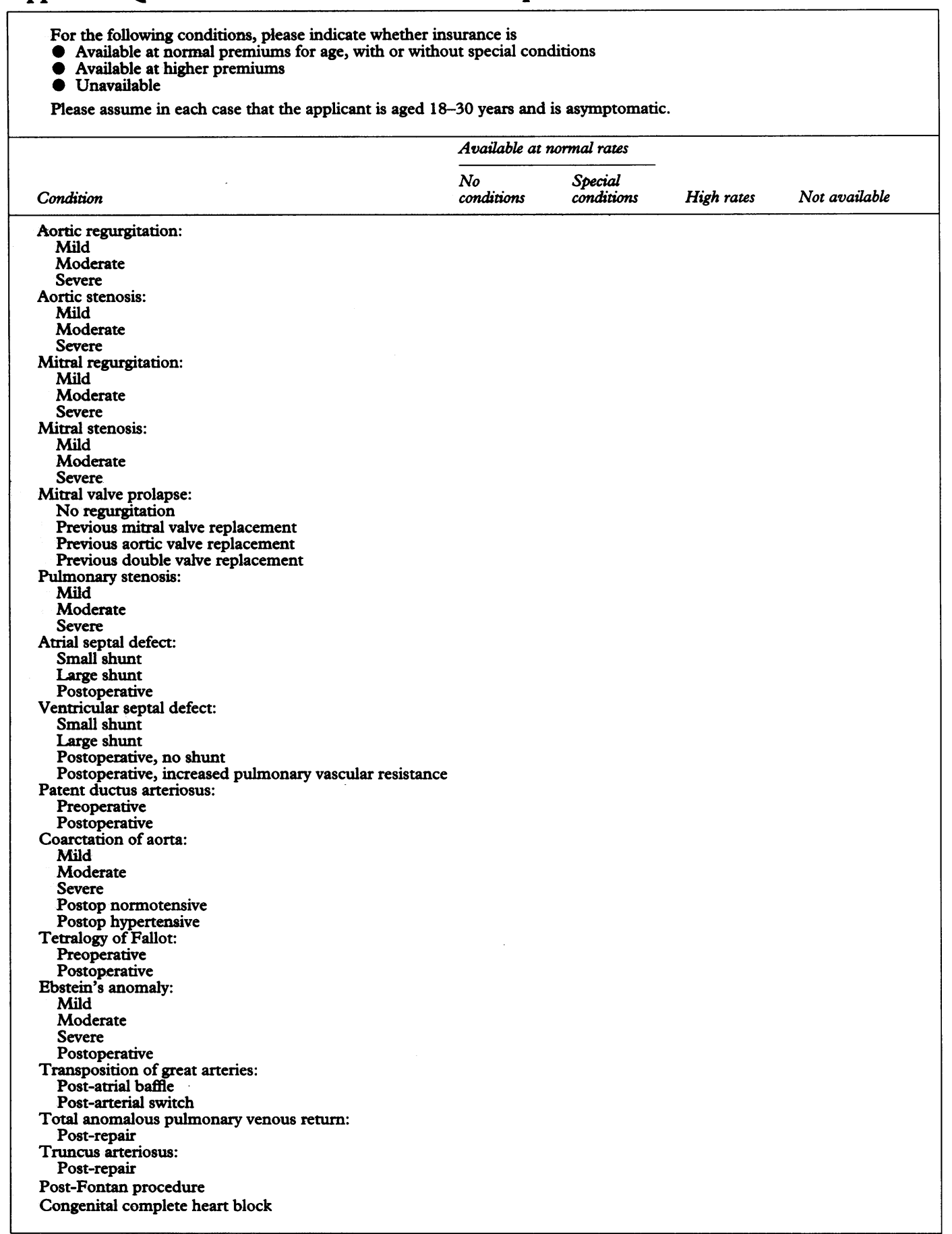

Responses fell into one of four categories:

(a) Employment is based solely on a functional assessment at the time of application. If applicants seemed physically capable of performing the required duties, they would be eligible for employment. This response was received from six employers, two of whom had occupational health advisors.

(b) Employment is based on a functional assessment and a medical opinion from the applicant's own general practitioner or cardiologist, or the company's own medical advisor. This might take into account prospects for future sick leave as well as current ability (from four employers).

(c) Employment is based on current ability to perform the task, future prospects for absenteeism, pension prospects where entry to a business is linked to entry to a pension fund, and future prospects of premature death or ill health in midlife, resulting in early career curtailment (from two employers). In this case, some young adults with heart disease might be at a disadvantage if they apply for jobs with a long period of apprenticeship or training.

(d) Employment is excluded for candidates with heart disease (from two employers). Other than the armed services, no employer had predetermined standardised policies for persons with a cardiac history. Several commented that the lack of employment guidelines and the ignorance of the long-term prognosis of some conditions may adversely 
prejudice the chances of some applicants with heart disease gaining long term employment, particularly for those with complex lesions. Two company medical advisors admitted a lack of knowledge of what some of the listed conditions represented.

\section{Discussion}

Most young adults with simple congenital heart disease can get life insurance (often at high rates), health insurance (with exclusion of their heart defect from the benefits policy), and employment. Most young adults with complex heart lesions cannot get life insurance, health insurance for their heart condition, or a job with long training programmes or linked to a pension fund.

One factor that greatly influences employment and insurance prospects is the severity of the disorder, as indicated by the applicant's physician. For example, a patient with mild aortic stenosis is eligible for life insurance, but one with moderate disease might be declined. Therefore, accurate grading of such lesions is of great importance.

The consensus of British life insurers for rating applicants with congenital heart disease (table) can be compared with a survey of American life insurers prepared by Truesdell et al. ${ }^{5}$ Results are broadly similar to those in our own survey, although most United States insurers accepted young adults after a Mustard or Senning procedure for transposition of the great arteries, whereas these subjects are declined by United Kingdom companies. Many insurance companies and doctors in Britian refer to data on medical selection of life risks compiled by Brackenridge, ${ }^{6}$ who suggests that most subjects with complex congenital heart lesions are uninsurable, and that those with simple lesions be insured only at high rating. These recommendations seem unduly harsh on the basis of more recently available data concerning the natural history; for example, young adults with mild pulmonary stenosis ${ }^{7}$ and those who have had successful repair of small atrial $^{8}$ or ventricular septal defects ${ }^{7}$ have an excellent long-term prognosis. By contrast some other ratings seem generous, such as normal rate insurance for postoperative coarctation of the aorta, given the recognised hazard for early mortality in large series. ${ }^{910}$ There are some significant inconsistencies in life insurance ratings between companies; therefore young adults declined by one company should "shop around" several others at which they may be insurable, albeit at high rates.

Inability to get health insurance is probably not critical for most young adults in Britain, where their care can currently be undertaken by the NHS. Inability to get life insurance, however, may be a serious disadvantage to a young adult who is married with or without dependent children and is looking for financial security for the future. Furthermore inability to gain life insurance may also make it difficult for many young adults with heart disease to buy their own home, as mortgage companies often require applicants to hold life insurance as suitable collateral.

There is no consensus among employers concerning prospects of young adults with heart disease. In part this may result from the fact that actuarial survival statistics are not $\underline{\underline{T}}$ available for most defects after early adult $I$ life. ${ }^{11}$ Most employers would like to think that new employees, particularly those who $\stackrel{c}{.}$

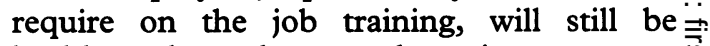
healthy when they reach retirement age. $\stackrel{\vec{s}}{+}$ Some young adults under our care have? found employment difficult to find, even if $\frac{\overline{\bar{C}}}{\bar{\rho}}$. they are symptom free and have a good prog- $\frac{\rho}{\sigma}$ nosis. They claim that some employers are $\varrho$ wary of any young person who admits to hav-ळ ing had a heart condition, whatever the $\vec{\circ}$ details. As a result many patients conceal $\overrightarrow{ }$ their cardiac history from prospective $\vec{\omega}$ employers. In the United States, the National Rehabilitation Act of 1973 has improved the employment prospects for any patient with a handicap, as emphasis must now be on the of present capacity of a person to perform a

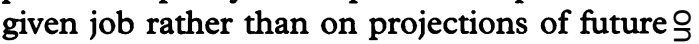
deterioration; no such law exists in Britain.The present capacity for a job relates to phys- $\frac{\complement}{\subseteq}$ ical capability, which is normal in many $\widehat{\varnothing}$ young adults with congenital heart disease, ${ }^{12} \vec{\varphi}$ intellectual capacity, which is also usually $\underset{\omega}{\oplus}$ normal in these subjects, ${ }^{13}$ and the require- $\square$ ment for any special skills, such as driving or flying. In this case safety of work colleagues or members of the public may be endangered if patients at risk of sudden disability or death $\frac{\varnothing}{\varnothing}$ are employed, and separate recommendations $\stackrel{\overrightarrow{7}}{\overrightarrow{7}}$ for driving and flying are available for young $\frac{3}{3}$ adults with congenital heart disease. ${ }^{14} 15$ Thus $=$ most patients with a postoperative congenital: cardiac defect should have access to employment. Specialised centres for the care of young adults with congenital heart disease $\frac{7}{\sigma}$ exist in Britain, and have a role in defining 3 . functional capacity and long-term survival prospects of this group, ${ }^{16}$ and in aiding indi- $\frac{3}{3}$ vidual patients in their search for botho

employment and insurance. ${ }^{17}$
As the paediatric cardiac successes of the modern era reach adulthood they face problems of both a medical and social nature. Although many with simple defects may get $\tilde{O}$ insurance and employment, prospects are less $N^{\circ}$ bright for those with complex defects or residual postoperative problems. Currento practice is not based closely on the available knowledge of natural history of congenital ${ }^{+}$ heart disease. As these data on natural and $\frac{T^{\circ}}{\circ}$ post operative survival become available, $\frac{\vec{D}}{\mathbb{P}}$ guidelines for employers and insurers should $\frac{P}{\mathbb{P}}$ be devised. In the absence of such guidelines,, some individual companies have set their own policies for young adults with congenital 8 heart disease. Unfortunately many other: companies have no policies on this subject, $\overline{0}$. and in these cases it is the patients who are? inappropriately disadvantaged.

We thank Mary Jane Potter for her secretarial assistance. 
1 Perloff JK. Congenital heart disease in adults. In: Kelly WN, ed. Textbook of internal medicine. Philadelphia: JB Lippincott, 1989,223-35.

2 Moller JH, Anderson RC. Natural history of congenital heart disease. 1000 consecutive children with cardiac malformations with 26-37 year follow-up. Am $f$ Cardiol 1992;70:661-7.

3 AHA committee report. Guidelines for insurability of patients with congenital heart disease. Circulation 1980;62:1419A-24A

4 Allen HD, Gersony WM, Taubert KA. Insurability of the adolescent and young adult with heart disease. Circulation 1992;86:703-10.

5 Truesdell SC, Skorton DJ, Laver RM. Life insurance for children with cardiovascular disease. Paediatrics 1986;77:687-91.

6 Brackenridge RDC. Medical selection of life risks. 2nd ed. London: Macmillan, 1985:240-61.

7 Report from the joint study on the natural history of congenital heart defects. Circulation 1993;87(suppl I): $1-126$.

8 Murphy JG, Gersh BJ, McGoon MD, Marr DD, Porter LJ, Ilstrup DM, et al. Long-term outcome after surgical repair of isolated atrial septal defect: follow-up at 27 to repair of isolated atrial septal defect: follow-
35 years. $N$ Engl $₹ M$ Med 1990;323:1645-50.

9 Cohen M, Fuster V, Steele PM, Driscoll D, McGoon DG. Coarctation of the aorta: long term follow-up and prediction of outcome after surgical correction. Circulation 1989;80:840-5.

10 Maron DJ, Humphries J, Rowe RD, Mellitts ED. Prognosis of surgically corrected coarctation of the aorta. Circulation 1973;47:119-26.

11 McNamara DG, Latson LA. Long-term follow-up of patients with malformations for which definitive surgipatients with malformations for which definitive surgi-
cial repair has been available for 25 years or more. $A m \mathcal{F}$
Cardiol $1982 ; 50: 560-7$

12 Cullen S, Celermajer DS, Deanfield JE. Exercise in congenital heart disease. Cardiol Young 1991;1: 129-35.

13 Whitman V, Drotar D, Lamberts S, Van Heeckeren DW, Borkat G, Arkeney J, et al. Effects of cardiac surgery with extracorporeal circulation on intellectual function in children. Circulation 1973;68:160-3. 14 Recommendations of the Secretary of State's Honorary
Medical Advisory Panel concerning cardiac conditions and drivers of heavy good vehicles and public service vehicles. Government General Health Trends. 1989; leaflet CLE1111.

15 Tunstall-Pedoe H. Acceptable risk in aircrew. Eur Heart $\mathcal{f}$ 1988;9(suppl G):9-11.

16 Somerville J. Congenital heart disease in adults and adolescence. Br Heart $\mathcal{F} 1986 ; 56: 395-7$.

17 Celermajer DS, Deanfield JE. Adults with congenital heart disease. $B M F$ 1991;303:1413-4. 